\title{
Alcohol in the heart, mostly poison and sometimes a cure: percutaneous transluminal septal myocardial ablation
}

\section{Marina Pavletić*, Željka Roginić, Patricia Kakarigi}

University Hospital Centre Zagreb, Zagreb, Croatia

\author{
KEYWORDS: alcohol septal ablation, hypertrophic cardiomyopathy. \\ CITATION: Cardiol Croat. 2018;13(1-2):60. | https://doi.org/10.15836/ccar2018.60
}

*ADDRESS FOR CORRESPONDENCE: Marina Pavletić, Klinički bolnički centar Zagreb, Kišpatićeva 12, HR-10000 Zagreb, Croatia. / Phone: +385-95-562-6804 / E-mail: marinapavletic@gmail.com

ORCID: Marina Pavletić, https://orcid.org/0000-0002-1165-7097• Željka Roginić, https://orcid.org/0000-0002-3381-0910 Patricia Kakarigi, https://orcid.org/0000-0001-8684-6477

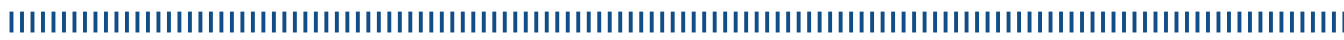

Alcohol in the heart can indeed be a cure. Percutaneous transluminal septal myocardial ablation or alcohol septal ablation (ASA) is one of the methods of treating hypertrophic cardiomyopathy. Hypertrophic cardiomyopathy is the most common genetic transmissible heart disease. Since 1994, alcohol septal ablation (ASA) has been used as a minimally invasive treatment of patients with hypertrophic obstructive cardiomyopathy, resistant to conservative medical therapy. This catheter-based intervention is performed by injecting alcohol into the septal branch to induce an infarction of the hypertrophied septum and thus reduce the obstruction of the left ventricle. This gradient reduction is associated with decreased symptoms and left ventricular remodeling. While surgical myomectomy was a gold standard by the end of the 1990s, alcohol septal ablation (ASA) has achieved rapid popularity and acceptance, especially in Europe. ${ }^{1}$

This review presents the process of preparation, performing the procedure and describing postprocedural care and potential procedural complications. If done in an experienced institution, ASA has a high rate of success and a low rate of complications. The procedure provides relief of symptoms and gives a similar longevity to patients as in the general population.
RECEIVED:

January 31, 2018

ACCEPTED:

February 10, 2018



$\square$ Cardiologia Croatica 2018:13(1-2):60.



1. Spaziano M, Sawaya FJ, Lefèvre T. Alcohol Septal Ablation for Hypertrophic Obstructive Cardiomyopathy: Indications, Technical Aspects, and Clinical Outcomes. J Invasive Cardiol. 2017 Dec;29(12):404-410. PubMed: https://www.ncbi.nlm.nih.gov/pubmed/29207362 